\title{
Strategies for the Collaborative Teaching of Physiological Sciences
}

\author{
Mario Vázquez-García* \\ Department of Physiology, Faculty of Medicine, México
}

*Corresponding author: Mario Vázquez-García, Department of Physiology, Faculty of Medicine, Universidad Nacional

Autónoma de México, Ciudad de México, México

\begin{tabular}{l} 
ARTICLE INFO \\
\hline Received: 蔧 November 24, 2020 \\
Published: 慧 November 30, 2020 \\
\hline
\end{tabular}

Citation: Mario Vázquez-García. Strategies for the Collaborative Teaching of Physiological Sciences. Biomed J Sci \& Tech Res 32(2)-2020. BJSTR. MS.ID.005222.

Keywords: Collaborative Teaching; Peer Instruction; Physiology; Active Learning

\begin{abstract}
Collaborative teaching is a powerful strategy that leads students to an effective and deep learning and to attain successful academic achievements. Collaborative learning exerts its influence through three important processes: cognitive, attitude, and behavioral. There are three different levels in the cognitive process in which collaborative teaching contributes to reach academic achievements: training, knowledge retention, and problem solving. Regarding attitude and behavioral processes, collaborative teaching fosters active participation and interest for peer discussion, research-based learning, the pleasure and motivation to learn. This review is centered on providing evidences on the efficacy of collaborative learning techniques for the teaching of physiology, including mainly their impact on learning and the academic achievement of students.
\end{abstract}

\section{Introduction}

An increasing body of evidence suggests that the collaborative learning strategies are intellectually stimulating, and their use provides an effective way of making students active learners. It is also assumed that these strategies help learners to develop and improve critical thinking skills, such as hypothesis testing, verbal reasoning, argumentation, decision-making, problem solving [2$5,8]$. The collaborative approach has been focused strongly on improving both the academic achievement and retention of the learned concepts. Methods like team-based learning, collaborative learning, cooperative learning, peer instruction, think-pair-share, collaborative-group testing, peer tutoring foster learning through social interaction. Furthermore, these methods arise from a fundamental premise: teaching of sciences must be supported largely on a universal scientific attitude [6]. In communication in the form of dialogue, there are four main elements that play an essential role in the collaborative approach:
a) Argumentation,
b) Controversy,
c) Discussion and
d) Debate $[2-5,7-12]$.

Academic activities in small groups are purported at having students talk and discuss their ideas or opinion about a topic in particular so that they can construct and reconstruct their own ways of representing their knowledge $[12,13]$. To learn through the communicative interaction is perhaps the most important generalization that can be made about this approach. In agreement with this notion, learning to discuss is considered the main fundament for a proficient academic learning to develop; on one side, scientific thinking and, on the other, identifying and using abstract concepts to construct new knowledge and/or solve a problem $[3,5,8,9,13]$.

In the collaborative learning, short tests become a regular practice of the students' daily activities, which allows for a more reliable evaluation of the student's progress and the appropriate supervision of the learning quality. The test has the advantage of allowing them to keep learning, knowing the level of the learned concepts, and acquire new knowledge. Besides, the paradigm 
can be used to assess the retention of learned concepts $[3,14,15]$ Knowledge expressed orally or in writing implies the risk of errors in its transmission and, hence, to give rise to misconceptions [13,15-17]. In the collaborative learning, after the discussion, students receive a feedback, strengthening thereby the efficiency of the learning process and preventing opportunely the acquisition of conceptual errors [18]. On the other hand, the practice of collaborative learning could help, on one side, to an integration of scientific advances and knowledge and, on the other side, to prepare students for their future professional activities.

\section{Collaborative Teaching of Physiological Sciences}

The physiology subject is part of the teaching programs of undergraduate and graduate studies in different fields of biological sciences and other professional disciplines $[1,11,19,20]$. Physiology deals with issues of normal function of organisms. Besides, physiology requires students to integrate knowledge from physics, chemistry, biophysics, biochemistry, cellular and molecular biology to understand how molecular and cellular interaction can affect the organic systems and the whole organism [21]. In recent decades, knowledge of the fundamental processes has flourished notably, and it appears that in the following decades there will be new important advances in the knowledge of the intricate physiological mechanisms. In view of foregoing, the higher education institutions and universities will be facing large challenges, i.e., the curricular design and the teaching of physiology.

Collaborative learning is centred on learning and adequate evaluation of the curricular contents, two key aspects for the effective teaching of physiology. Many investigators have revealed the essential role of the multiple-choice testing to assess the advancement of students in comprehending the physiology concepts. According to the literature on the teaching of physiology, results confirm that the collaborative teaching methods yield better academic results than those based on conventional teachings. In one of the first studies that had a considerable influence, Beaton and Mitchell in 1979 [22] described for the first time the collaborative teaching as an alternative approach to the traditional teaching of physiology. Their article showed convincingly the contribution of the collaborative approach to active and student-centred learning and oriented to problem solving. They chose third-year medical students attending the physiology course. The teaching strategy was an interesting innovation, there were no lectures, tutorials, or laboratory practices; more than receiving information, students had the obligation of compiling and registering it. All academic activities were developed in small groups of students. Perhaps the most striking differences between this approach and the traditional arise when students are required to teach, learn, and evaluate their fellows, as well as exert self-evaluation. This educational experience fostered the integrated understanding of concepts and helped positioning physiology in its due perspective for the medical practice. Positive attitudes were also perceived toward this collaborative proposal, pointing out that learning is the responsibility of the learner. This study revealed new perspective and ideas on how to improve the higher education system.

The great influence of the collaborative teaching approach on learning has been revealed in further research that not only corroborated the contributions of the Beaton and Mitchell study [22], but also evaluated quantitatively its impact on the academic performance of students. At the end of the nineties, Lake [23] demonstrated for the first time the effectivity of peer tutoring on the teaching of sciences in the university. This study revealed that students being tutored by their fellows of higher courses had a better academic performance in the advance physiology course than their non-tutored peers. Besides, students reasserted the great relevance of participating in the implementation of peer tutoring, as well as their interest in continuing to participate in future courses within this educational instruction. An additional powerful model of collaborative teaching is the instruction among peers. In this model, after a lecture of some minutes, one or several multiple-choice questions are posed regarding the just covered topic. Students use 1 to 2 minutes to answer the posed questions, initially in an individual manner and afterward they use 1 to 2 minutes to answer the same questions in collaboration with the members of their team [3].

In general, the questions of the tests were developed according to the six general levels of Bloom's taxonomy of the cognitive level [24]. In 2000, Rao and DiCarlo [10] reported that the peer instruction significantly increased the percentage of correct answers in respiratory physiology tests. As are common, medical students presented twice the same multi-choice test, the first time they took it individually and subsequently they answered it through a group discussion. These discussions were particularly useful for the students as the average percentages of their correct response increased significantly after the discussions. In addition, the average grades were usually better in the items of the tests constructed to assess the higher order cognitive skills, suggesting that students developed a profound conceptual understanding [24,25]. Similarly, but to a lesser extent, there was an improvement in the answers to the questions that assessed lower order cognitive skills. In the last years, it has been shown that peer instruction increases the learning level of the contents of cardiovascular, respiratory, and renal physiology $[11,16,17,19,26-28]$, of exercise physiology [29], of acid-base physiology [19,30,31], of nervous system and hemato encephalic barrier physiology [11,20], excitability [32] and of a laboratory course of physiology [16,33,34].

It is worthwhile noting the essential role played by collaborative teaching in improving the academic achievement in both students with higher and lower individual grades. However, benefits have been greater for those students with lower grades than for 
those with higher grades. More importantly, team conversations have produced more benefits particularly when there has been dissensus more than consensus in the individual responses of the team's members. Debates on the different perspective had a positive effect on the learning by students, supporting the notion that peer argumentation in the classroom practice can contribute to the improvement of the students' understanding of theoretical concepts of physiology $[1,2,11,14,35]$. On the other hand, it has also been documented that peer instruction increases the skill to solve new problems [36]. It must be pointed out that the collaborative approach has also offered perspectives about the retention of physiology concepts. A serious risk for retention of learning of sciences is implicit in the decay of the learned concepts from memory. Information processed in a rehearsal memory system can delay and/or avoid the decay of the learned material from memory. Thus, the information can be stored in memory for a long time and be retrieved later from memory storage. In the collaborative learning, after the lecture on a particular physiology topic, students can evoke the concepts several times. For example, after the lecture, they complete twice the same quiz, discuss with their peers and, finally, with the professor; thus, a topic is revised several times in the same class, which implies a better learning experience.

Many studies now have demonstrated that the collaborative methods increase the possibility that the information stored in the short-term memory can be coded in the long-term memory. To estimate the learned knowledge, an initial test is followed an interval of several weeks by a retention test, with the characteristic that both tests examine the same contents [37]. For example, knowledge on exercise, cardiovascular, respiratory, and renal physiology lasted at least between 1 and 4 weeks after the student had taken those lessons $[11,29,38]$. Evidence also exists that students retain the learned acid-base concepts for 24 months [30]. All these observations suggest that the collaborative approach promotes consolidation of knowledge toward a long-term learning and memory [39].

In summary, all the teaching strategies that aim at helping students to construct a knowledge based on collaborative experiences in the classroom practice have been more successful than the conventional tactics centred on the teacher. Furthermore, the most profound impact of the collaborative methods is on the capacity of students to develop a deeper comprehension of fundamental physiological concepts [10,11,26-28]. The collaborative approach has been associated with higher academic achievements, the application of knowledge and critical thinking, better problem solving, and retention of the learned material for prolonged time periods. Collaborative teaching in the physiology course has been used successfully in large groups [10], it has helped to motivate students to remain keep up with their lessons, and to have a better perception of their control on the learning process, it has influenced positively their attitude and promoted social interaction $[16,29,33,34]$. Finally, the methods and skills used by the professors become more effective in attracting and maintaining the attention of their students, in fomenting a more positive relation between students and their professor, and a better wellbeing sensation, all of which can help students develop resilience in their pursuit of physiology knowledge [11,29].

\section{References}

1. Giuliodori MJ, Lujan HL, Di Carlo SE (2009) Student interaction characteristics during collaborative group testing. Advances in Physiology Education 33(1): 24-29.

2. Kuhn D (2010) Teaching and learning science as argument. Science Education 94(5): 810-824.

3. Mazur E (1997) Peer instruction: getting student to think in class. AIP Conference Proceedings 399(981).

4. Michael J (2006) Where's the evidence that active learning works? Advances in Physiology Education 30(4): 159-67.

5. Osborne J (2010) Arguing to learn in science: The role of collaborative, critical discourse. Science 328(5977): 463-466.

6. (1989) American Association for the Advanced of Science. Science for All Americans: Project 2061. New York: Oxford Univ. Press.

7. Ford MJ (2012) A dialogic account of sense-making in scientific argumentation and reasoning, Cognition and Instruction 30(3): 207245 .

8. Goodsell AS, Maher MR, Tinto V (1992) Collaborative learning: A sourcebook for higher education. Syracuse, NY, National Center on Postsecondary Teaching, Learning \& Assessment, Syracuse University.

9. Lyman FT (1981) The responsive classroom discussion. In: AS Anderson (Eds) Mainstreaming Digest College Park, MD: Univ. of Maryland College of Education pp. 109-113.

10. Rao SP, DiCarlo SE (2000) Peer instruction improves performance on quizzes. Advances in Physiology Education 24(1): 51-55.

11. Vázquez-García M (2018) Collaborative-group testing improves learning and knowledge retention of human physiology topics in second-year medical students. Advances in Physiology Education 42(2): 232-239.

12. Vygotsky LS (1978) Mind in society: The development of higher psychological processes. Cambridge, MA: Harvard University Press.

13. Patel VL, Yoskowitz NA, Arocha JF, Shortliffe EH (2009) Cognitive and learning sciences in biomedical and health instructional design: A review with lessons for biomedical informatics education. Journal of Biomedical Informatics 42(1): 176-197.

14. Giuliodori MJ, Lujan HL, DiCarlo SE (2008) Collaborative group testing benefits high- and low- performing students. Advances in Physiology Education 32(4): 274-278.

15. Hunt E, Pellegrino W (2002) Issues, examples, and challenges in formative assessment. New Directions for Teaching and Learning 89: 73-85.

16. Carvalho H, West CA (2011) Voluntary participation in an active learning exercise leads to a better understanding of physiology. Advances in Physiology Education 35(1): 53-58.

17. Versteeg M, van Blankenstein FM, Putter H, Steendijk P (2018) Peer instruction improves comprehension and transfer of physiological concepts: a randomized comparison with self-explanation. Advances in Health Science Education: Theory and Practice 24(1): 151-165.

18. Hattie J, Temperley $H$ (2007) The power of feedback. Review of Educational Research 77(1): 81-112. 
19. Leehey DJ, Daugirdas JT (2016) Teaching renal physiology in the 21st century: focus on acid-base physiology. Clinical Kidney Journal 9(2): 330-333.

20. Nelson RK, Chesler NC, Strang KT (2013) Development of concept-based physiology lessons for biomedical engineering undergraduate students. Advances in Physiology Education 37(2): 176-183.

21. Modell HI (2007) Helping students make sense of physiology mechanism: the view from inside. Advances in Physiology Education 31(2): 186-192.

22. Beaton G, Mitchell D (1979) Physiology. Medical Teacher 1(2): 71-5.

23. Lake DA (1999) Peer tutoring improves student performance in an advanced physiology course. The American Journal of Physiology 21(1): S86-92.

24. Hopkins KD, Stanley JC, Hopkins BR (1990) General principles of test construction: achievement measures. In: Educational and Psychological Measurement and Evaluation, $7^{\text {th }}$ (Edn). Englewood Cliffs NJ: Prentice Hall pp. 165-192.

25. Crowe A, Dirks C, Wenderoth MP (2008) Biology in bloom: Implementing Bloom's taxonomy to enhance student learning in biology. CBE-Life Sciences Education 7(4): 368-381.

26. Giuliodori MJ, Lujan HL, DiCarlo SE (2006) Peer instruction enhanced student performance on qualitative problem-solving questions. Advances in Physiology Education 30(4): 168-173.

27. Krontiris-Litowitz J (2009) Articulating scientific reasoning improves student learning in an undergraduate anatomy and physiology course. CBE-Life Sciences Education 8(4): 309-315.

28. Rao SP, Collins HL, DiCarlo SE (2002) Collaborative testing enhances student learning. Advances in Physiology Education 26(1): 37-41.

29. Cortright RN, Collins HL, Rodenbaugh DW, DiCarlo SE (2003) Student retention of course content is improved by collaborative-group testing. Advances in Physiology Education 27: 102-108.

\section{ISSN: 2574-1241}

DOI: $10.26717 /$ BJSTR.2020.32.005222

Mario Vázquez-García. Biomed J Sci \& Tech Res

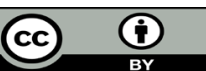

This work is licensed under Creative Commons Attribution 4.0 License

Submission Link: https://biomedres.us/submit-manuscript.php
30. Hartmann JP, Toksvang LN, Berg RM (2015) Collaborative teaching strategies lead to retention of skills in acid-base physiology: a 2-yr follow-up study. Advances in Physiology Education 39(2): 120-121.

31. Petersen MW, Toksvang LN, Plovsing RR, Berg RM (2014) Collaborative strategies for teaching common acid-base disorders to medical students. Advances in Physiology Education 38(1): 101-103.

32. Albuquerque FDS, Assis TS, Oliveira Júnior, FA Freitas, MR Sá, et al. (2018) Effect of the use of a model with peer instruction for the teaching of membrane potential and action potential. Advances in Physiology Education 42(4): 661-667.

33. Bian H, Bian Y, Li J, Li Y, Ma Y, et al. (2018) Peer instruction in a physiology laboratory course in China. Advances in Physiology Education 42(3): 449-453.

34. Jensen MS (1996) Cooperative quizzes in the anatomy and physiology laboratory: a description and evaluation. The American Journal of Physiology 271(6): S48-54.

35. Relling AE, Giuliodori MJ (2015) Effect of peer instruction on the likelihood for choosing the correct response to a physiology question. Advances in Physiology Education 39(3): 167-171.

36. Cortright RN, Collins HL, DiCarlo SE (2005) Peer instruction enhanced meaningful learning: ability to solve novel problems. Advances in Physiology Education 29(2): 107-111.

37. Haynie WJ (1994) Effects of Multiple-choice and short-answer tests on delayed retention learning. Journal of Technology Education 6(1): 32-44.

38. Srivastava TK, Waghmare LS, Mishra VP, Rawekar AT, Quazi N, et al. (2015) Peer teaching to foster learning in physiology. Journal of Clinical and Diagnostic Research 9(8): JC01-6.

39. Kandel ER, Schwartz JH, Jessell TM, Siegelbaum SA, Hudspeth AJ (2013) Principles of neural science, $5^{\text {th }}$ (Edn). McGraw-Hill, New York, USA.

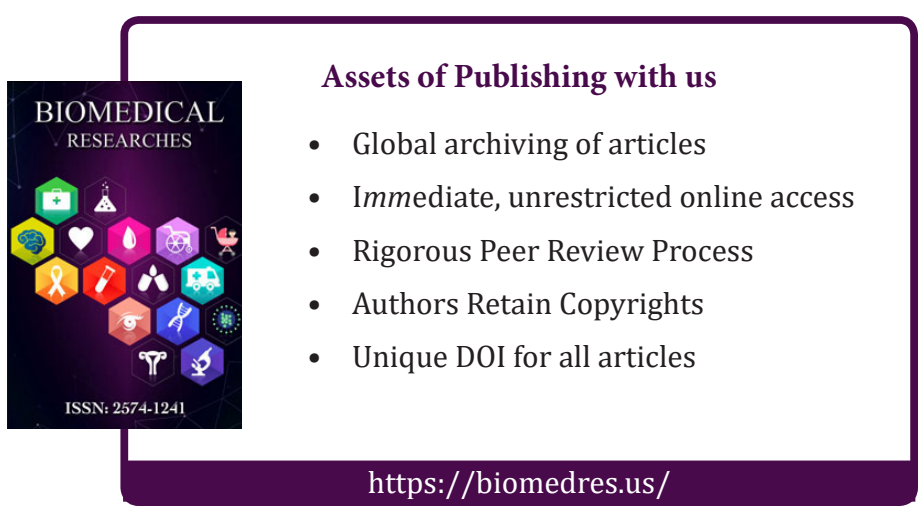

